\title{
Design, Fabrication, and Analysis of Miniature Centrifugal Pump
}

\author{
Pankaj V. Patil, Digambar S. Pawar, Chetan S. Mote, \\ Ashutosh B. Deshmukh, Subhash V. Jadhav
}

\begin{abstract}
In this paper, an experimental analysis is carried out for a mini-centrifugal pump, which is fabricated by an advanced manufacturing technology like 3D Printing. A small electric motor is used to drive the pump of 15 cmimpeller diameter, and it is validated for its performance in terms of discharge with the results available in the literature.

Further, the performance of the pump is discussed in terms of other parameters. The discharge of the pump is found to be decreased with increasing head.Similarly, the voltage required for the pumping is found to be increasing with the pumping head. The mini-pump used in the study is found to be perform similar to that of a macro-pump with respect to the discharge of the pump.
\end{abstract}

Index Terms- Centrifugal pump, Mini pump, Impeller, 3D printing, Discharge, Head.

\section{INTRODUCTION}

For moderate discharge and moderate heads, the centrifugal types of pumps are nowadays preferred widely.Centrifugal pumps are used to transport fluids, where rotational kinetic energy is converted into the hydrodynamic energy of the fluid flow. A pump is a device which lifts the water from a lower pressure to higher pressure area.centrifugal pump uses centrifugal force to suck the liquid from a lower level. The impeller is the most critical part of the pump which is rotated by the prime mover, and due to rotation it creates the pressure head and at the center of impeller pressure lower and this pressure helps to lift the water. Many industries are effectively using the centrifugal pump for various applications. Many of the researchers have put a considerable effort to increase the efficiency of the pump. The various study has been done, to date on the various factor related to the centrifugal pump. The study related to change in the impeller design, geometry, number of vanes, outlet angles, the material of the impeller, etc. Shuhong Liu et al. studied geometry using the design procedure and found that design procedurehas a considerable effect on its performance[1].

Pankaj V. Patil, Mech. Engg Dept., SVERI's COE, Pandharpur, India Digamba .S. Pawar Mech. Engg Dept., SVERI's COE, Pandharpur, India Chetan S. Mote, Mech. Engg Dept., SVERI's COE, Pandharpur, India Ashutosh B. Deshmukh, Mech. Engg Dept., SVERI's COE, Pandharpur, India

Subhash V. Jadhav, Asst.. Professor, Mech. Engg Dept., SVERI's COE, Pandharpur, India

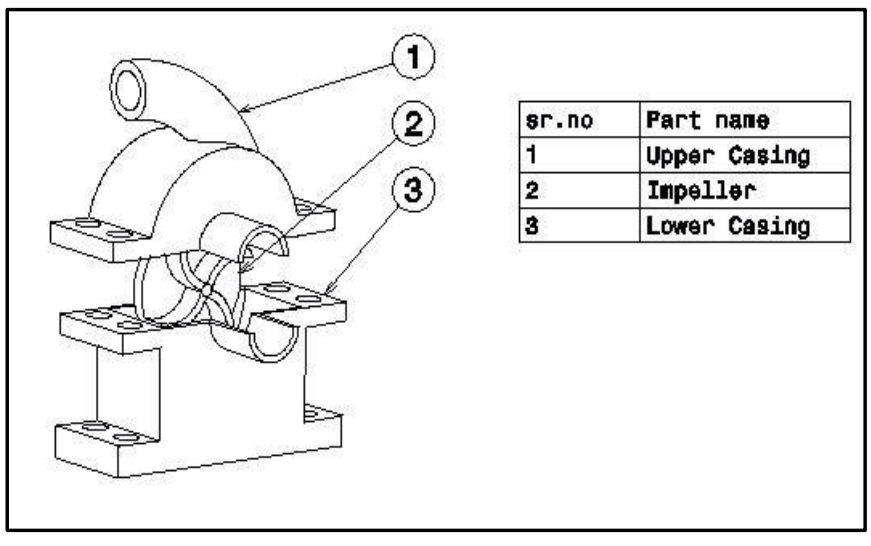

Fig 1 . The mini-centrifugal pump used in this study.

Nilesh Patil et al. studied the CFD analysis of the pump for various functional parameters of the centrifugal pump from which it is seen that the modified design of centrifugal pump consumes less power than the conventional design. Due to this, there is an improvement in efficiency [2]. Khin Cho Thin et al. studied the variouslosses occurs in thecentrifugal pump which are friction losses at impeller and casing and which causes a decrease in efficiency of the pump. By studying various graphs ( $\mathrm{H}$ vs. Q) that he presented it is seen that by increasing the head, discharge is reduced[3]. Hongchang Dinget al. studied the characteristic of a centrifugal pump by changing the blade outlet angle. From this is seen that efficiency is dependent on the outlet blade angle[4]. Zhang Ning et al. studied the effect of changing blade trailing edge on the static pressure development on the blades it is seen that after modifying the blade it truly affects the pump head particularly for higher flow rate head is increases.[5]. Georgios Mousmoulis et al. studied the cavitation in centrifugal pump using acoustic emission .is seen that the cavitation increases with increase in the flow rate and the occurrence of the bubble is always at the suction side[6]. Gamal R.H et al. studied the effect of a number of blades on the performance of impeller. From his work, it is seen that as we increase the blade number, there is a decrease in thepitch ratio also there is an increase in the friction losses. Hydraulic losses are also increased [7].Rui $\mathrm{Yu}$ and Jinxiang Liucarried out a study on the failure analysis if centrifugal pump. The mechanical properties due to the degradation of the microstructure of impeller material. Also, it is seen that impeller failure material has a lower elastic modulus [8]. 
Many of the researchers are studied the macro size centrifugal pumps, but very few workshavebeen done related to mini pumps.So, this is an attempt for the design and behavior of mini-centrifugal pump (Fig. 1) undervaryingoperatingconditions. The performance is analyzed in terms of discharge of the pump and power required for its operation.

\section{DESIGN PROCEDURE}

Step 1: calculate the pump specific speed

$$
\mathrm{N}_{\mathrm{s}}=\frac{\mathrm{N} \times \sqrt{\mathrm{Q}}}{\mathrm{H}^{\frac{3}{4}}}
$$

Step2. Selecting a vane number and discharge angle.

Selected vane numbers for the mini pump considered is 4 . For this many vanes, the discharge angle is considered as $20^{\circ}$.

Step 3. Calculating impeller diameter.

Headconstant $(\mathrm{Ku})=1.18$

$$
\mathrm{D}_{2}=\frac{1840 \times \mathrm{K}_{\mathrm{u}} \times \sqrt{\mathrm{H}}}{\mathrm{N}_{\mathrm{s}}}
$$

Step 4. Calculate impeller width b2.

$$
\begin{aligned}
& \mathrm{S}_{\mathrm{u}}=0.5 \mathrm{inch} \quad \mathrm{Km}_{2}=0.13 \\
& \mathrm{Cm}_{2}=\mathrm{Km}_{2} \times \sqrt{2 \mathrm{gH}}
\end{aligned}
$$

Step 5. Determine Eye diameter

$$
\frac{\mathrm{D}_{1}}{\mathrm{D}_{2}}=0.58
$$

\section{Step 6. Estimating Eye area}

$$
\text { Eye Area }=\frac{\pi}{4} \times\left(D_{1}{ }^{2}-d^{2}\right)
$$

Step 7. Estimating the Net positive suction head $\left(\mathrm{N}_{\mathrm{ss}}\right)$

$$
\begin{gathered}
\mathrm{Cm}_{1}=\frac{\mathrm{Q} \times 0.321}{0.1834} \\
U \mathrm{t}=\frac{\mathrm{D}_{1} \times \mathrm{N}_{\mathrm{s}}}{229} \\
\mathrm{~N}_{\mathrm{ss}}=\frac{\mathrm{N}_{\mathrm{s}} \sqrt{\mathrm{Q}}}{\mathrm{H}^{\frac{3}{4}}}
\end{gathered}
$$

The value of $\mathrm{H}$ is obtained from the results obtained during the analysis. Design procedure mentioned by ROBERT .R. Ross is used. Knowing the values of $\mathrm{cm} 1$ and Ut, we can find the value of Nss.

\section{Step 8. Determining the Volute Parameters}

$$
\text { Volute Area }\left(A_{8}\right)=\frac{0.04 \times Q}{K_{3} \times \sqrt{H}}
$$

Step 9) Estimating the volute width :-

$$
b_{3}=1.72 \times b_{2}
$$

Step10) Cut water diameter :-

$$
D_{3}=D_{2} \times 1.09
$$

\begin{tabular}{|ll|}
\hline \multicolumn{2}{|l|}{ Nomenclature } \\
\hline $\mathrm{Cm} 2$ & $=$ Radial velocity at impeller discharge \\
\hline $\mathrm{b}_{2}$ & $=$ Inside impeller width \\
\hline $\mathrm{A}_{8}$ & $=$ Volute throat area \\
\hline $\mathrm{Vr}_{1}=\mathrm{W} 1=$ Relative velocity of flow \\
\hline $\mathrm{C}_{1} \quad=$ Absolute velocity of flow \\
\hline $\mathrm{d}$ & $=$ diameter of shaft. \\
\hline $\mathrm{Su}$ & $=$ Vane thickness \\
\hline $\mathrm{Cm}$ & $=$ Suction eye velocity. \\
\hline $\mathrm{Ut}_{1}$ & $=$ peripheral velocity of impeller blade \\
\hline $\mathrm{g}$ & $=$ Gravitation constant \\
\hline $\mathrm{Km}_{2} \quad=$ capacity constant \\
\hline $\mathrm{D}_{1} \quad=$ Diameter of impeller. \\
\hline
\end{tabular}

Table No 1 Design parameters of the miniature centrifugal pump

\begin{tabular}{|l|l|l|l|l|l|}
\hline $\begin{array}{l}\text { RPM } \\
\text { (N) }\end{array}$ & $\begin{array}{l}\text { Discharge } \\
\text { (Q)GPM }\end{array}$ & $\begin{array}{c}\text { Head } \\
\text { (H)feet }\end{array}$ & $\begin{array}{c}\text { Ns } \\
\text { (RPM) }\end{array}$ & $\begin{array}{c}\mathbf{D}_{\mathbf{2}} \\
\text { (inch) }\end{array}$ & $\begin{array}{c}\mathbf{C m}_{\mathbf{2}} \\
(\mathbf{f t} / \mathbf{s})\end{array}$ \\
\hline 3700 & 0.48 & 0.99 & 2570.72 & 0.84 & 1.04 \\
\hline 3484 & 0.48 & 0.82 & 2787.52 & 0.71 & 0.92 \\
\hline
\end{tabular}

\begin{tabular}{|c|c|c|c|c|l|}
\hline $\begin{array}{l}\mathbf{b}_{2} \\
(\text { inch })\end{array}$ & $\begin{array}{l}\mathbf{D}_{\mathbf{1}} \text { (fee } \\
\mathbf{t})\end{array}$ & $\begin{array}{l}\text { Eye area } \\
(\mathbf{s q . i n})\end{array}$ & $\begin{array}{l}\mathbf{C m}_{1} \\
(\mathbf{f t} / \mathbf{s})\end{array}$ & $\begin{array}{l}\mathbf{U}_{\mathbf{t}} \\
(\mathbf{f t} / \mathbf{s})\end{array}$ & $\begin{array}{l}\mathbf{N}_{\text {ss }} \\
(\mathbf{R P M})\end{array}$ \\
\hline 0.23 & 0.49 & 0.18 & 0.84 & 5.47 & 8136.41 \\
\hline 0.75 & 0.41 & 0.13 & 1.21 & 4.98 & 8822.59 \\
\hline
\end{tabular}

A minimum gap must be kept in between the impeller and the volute lip to prevent it from noise, pulsation, and vibration and which is called as cut water diameter $\left(\mathrm{D}_{3}\right)$. The design parameters calculated according to the design procedure are presented in Table 1 and dimensions of volute diameter and width is tabulated below in the table No.2.

Table No. 2 dimensions of volute diameter and width

\begin{tabular}{|c|c|c|c|}
\hline Sr.No & $\begin{array}{c}\text { Volute area } \\
\text { (sq.in) }\end{array}$ & $\begin{array}{c}\text { Volute width } \\
\text { (b3) }\end{array}$ & D3 \\
\hline 1 & 0.08 & 0.40 & 0.92 \\
\hline 2 & 0.09 & 1.29 & 0.77 \\
\hline
\end{tabular}

\section{MODELING OF IMPELLER AND PUMP}

CATIA V5, a commercial modeling software, is used for the modeling of the mini-pump. The modeling is done as per the dimension calculated using the design mentioned in the above procedure. The models of the impellerproduced by 
CATIA v5 software is as shown in fig2. The Impeller is designed by considering the velocity triangles and other design parameters. The critical design parameter in impeller design is the outlet angle of the impeller. After the impeller design, the designing of the volute is done. The cut water diameter plays a vital role in the volute design. Fig3. Shows the CATIA model of the entire assembly of the upper casing, lower casing, and the impeller.

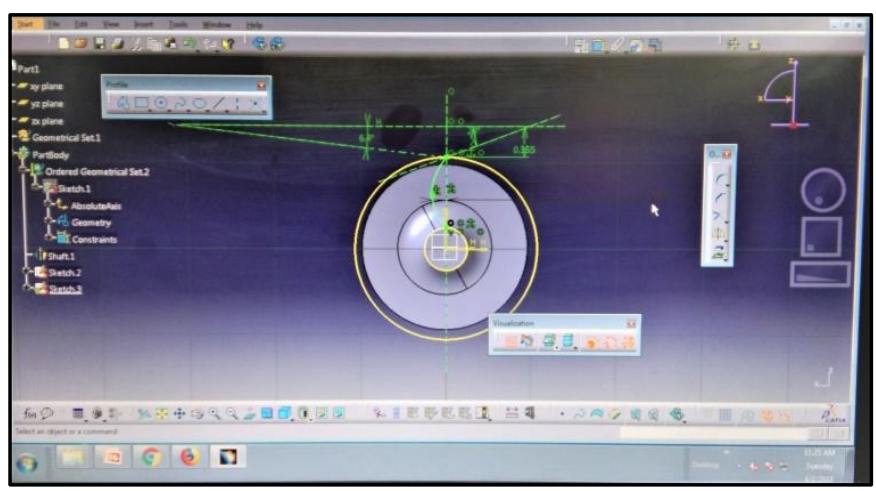

Fig2. Modeling of Impeller

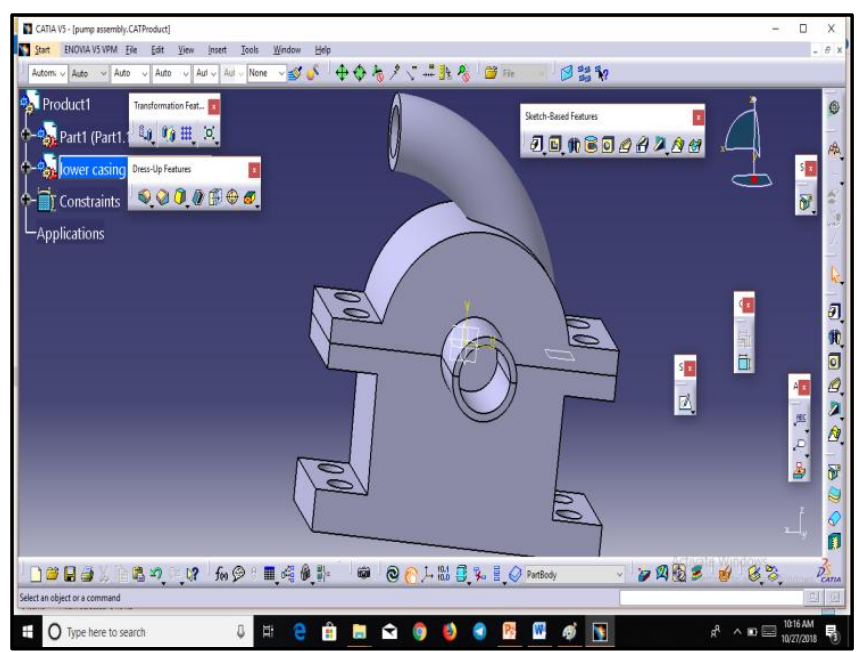

Fig. 3. Modeling of the Upper and lower casing of the pump

\section{FABRICATION OF PUMP}

Fabrication may be defined as a manufacturing process in which an item is made from semi-finished materials instead of being assembled from ready-made components or parts. The parts of the pump such as impeller, casing, outlet, inlet are fabricated using the advanced manufacturing equipment which is $3 \mathrm{D}$ printing $.3 \mathrm{D}$ printing machine is an advanced machine which produces the three dimensional Solid parts. In this machine, the material is joined or solidified under the computer control layer by layer. 3D printing uses the rapid prototyping technique. Parts which are designed in CATIA v5 is converted into a ".stl" format, and this input is given to the machine. Preheating is an essential and foremost condition because the surface where the component may be printed and the extruder which melts the material has to be in a heated condition. Until and unless the preheating is not over the printing will not start.
The fabricated parts by using 3D Printing is shown in fig 4.The assembled pump is then used for further analysis, where it is coupled with an electric motor for its propelling.

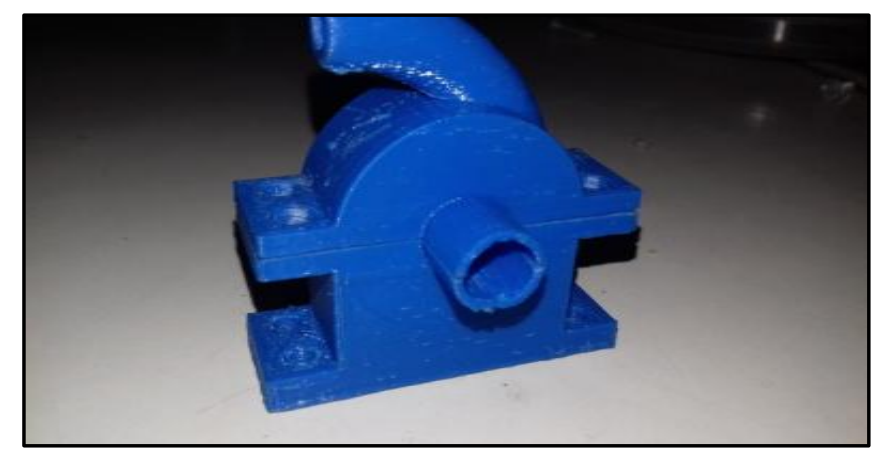

Fig. No. 4 Fabricated model of the pump

\section{VALIDATION OF BASELINE MODEL}

The discharge obtained for the centrifugal pump modeled and fabricated as mentioned above is compared with the discharge performance available in the literature [9] John et al. This performance is shown in figure 5. the comparison shows that the trend attained with the mini-pump used in this work is almost similar to that of the trend in the literature. The pump used in this work falls in the category of the mini pump, Obliviously, the discharge values obtained are comparatively smaller. However, the trend of the graph remains the same as that of the macro pump used by John et al. Therefore, the results obtained in this work can be considered as validated.

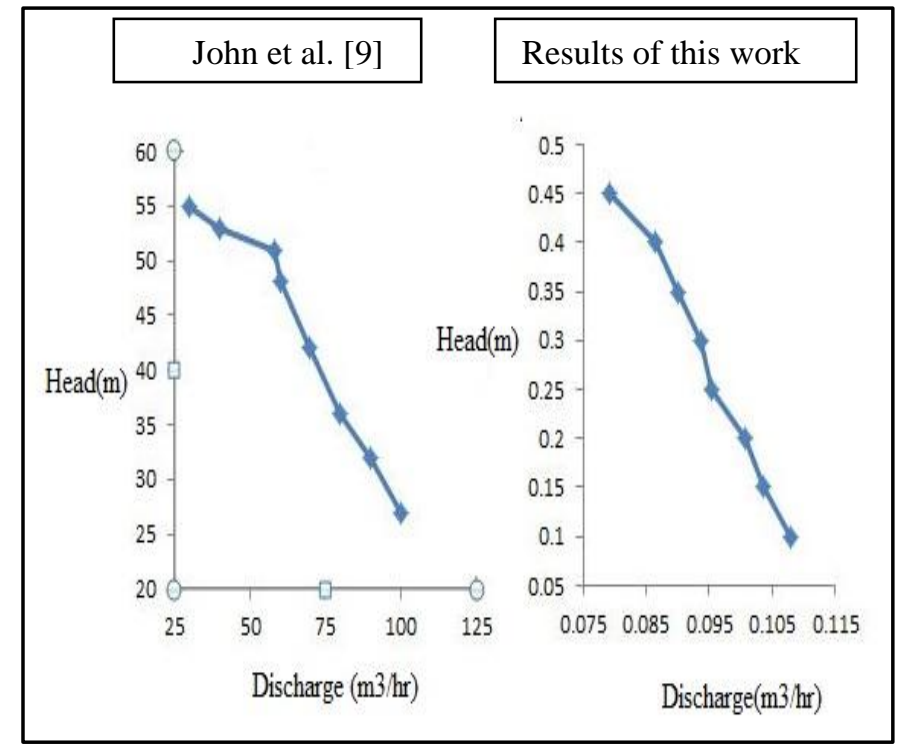

Fig 5. Validation of Fabricatedbaseline model of pump

\section{PERFORMANCEANALYSIS OFTHE PUMP}

The experimentation done on thecentrifugal pumpis discussed in this section.The parameters such as discharge, Head, Voltage, and RPM of the impeller are studied under varying conditions and the experimental results obtained are 
plotted. When the Head is varied from $10 \mathrm{~cm}$ to $50 \mathrm{~cm}$, the values of discharge $(\mathrm{ml} / \mathrm{min})$ is observed to be decreasing from $30 \mathrm{ml} / \mathrm{min}$ to $20 \mathrm{ml} / \mathrm{min}$. Figure 6 shows this trend obtained with the fabricated pump. When the input voltage supplied to the motor used for driving the pump is changed from $2 \mathrm{~V}$ to $6 \mathrm{~V}$, the head is observed toincrease as shown in figure 7 .

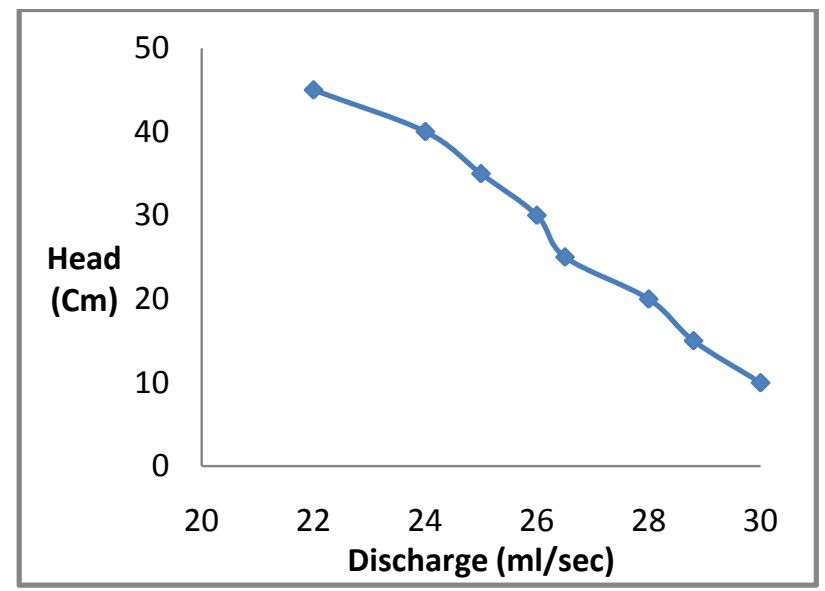

Fig. 6 Head vs.Discharge for modifiedpump

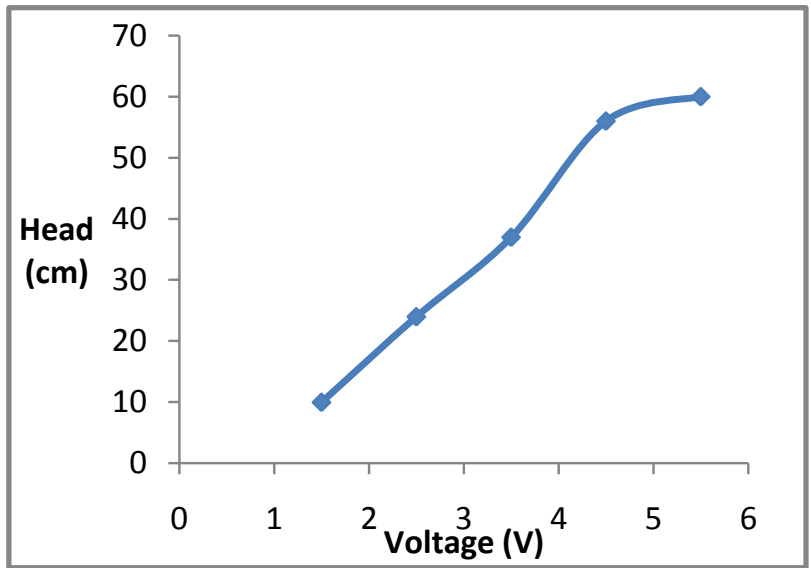

Fig. 7 Head Vs Voltage for modified pump

\section{CONCLUSION}

Mini-pumps fabricated with 3D fabrication technique are analyzed in this paper.The mini-pumps can be considered as a viable option for the different smaller discharge required in applications like medical and microfluidics etc. The following observations can be made from the above analysis.

1.The discharge of the centrifugal pump is found to be decreasing with an increase in the pumping head.

2. The voltage required for driving the centrifugal pump is found to be increased when the pumping head is increased.

3. The performance of the mini-pump used in this study is found to be similar,in terms of discharge,to that of a standard macro pump.

\section{REFERENCES}

[1] S. Liu, M. Nishi, and K. Yoshida, "Impeller Geometry Suitable for Mini Turbo-Pump," J. Fluids Eng., vol. 123, no. 3, p. 500, 2002.

[2] N. Patil, P. G. S. Joshi, and P. V. R. Naik, "Validation in the improved performance of Centrifugal pump using CFD," Int. Res. J. Eng. Technol., vol. 4, no. 6, pp. 1674-1678, 2017.

[3] H. Ding, Z. Li, X. Gong, and M. Li, "The influence of blade outlet angle on the performance of centrifugal pump with a high specific speed," Vacuum, vol. 159, no. August 2018, pp. 239-246, 2019.

[4] N. Zhang, X. Liu, B. Gao, X. Wang, and B. Xia, "Effects of modifying the blade trailing edge profile on unsteady pressure pulsations and flow structures in a centrifugal pump," Int. J. Heat Fluid Flow, vol. 75, no. April 2018, pp. 227-238, 2019

[5] G. Mousmoulis, N. Karlsen-Davies, G. Aggidis, I. Anagnostopoulos, and D. Papantonis, "Experimental analysis of cavitation in a centrifugal pump using acoustic emission, vibration measurements and flow visualization," Eur. J. Mech. B/Fluids, vol. 75, pp. 300-311, 2019.

[6] G. R. H. Abo Elamin, M. A. Bassily, K. Y. Khalil, and M. S. Gomaa, "Effect of impeller blades number on the performance of a centrifugal pump," Alexandria Eng. J., 2019.

[7] R. Yu and J. Liu, "Failure analysis of centrifugal pump impeller," Eng. Fail. Anal., vol. 92, no. June, pp. 343-349, 2018.

[8] John S. Anagnostopoulos," A fast numerical method for flow analysis and blade design in centrifugal pump impellers," Computers \& Fluids, Vol. 38, pp. 284-289,2009. 